\title{
Correction to: Ultrastructural and Immunohistochemical Diagnosis of a Neonatal Herpes Simplex Virus Infection Presenting as Fulminant Hepatitis: A Case Report
}

Valentina Papa, Nunzio Cosimo Mario Salfi, Roberta Costa, Ilaria Bettocchi, Emilia Ricci, Duccio Maria Cordelli, Francesca Locatelli, Fabio Caramelli, and Giovanna Cenacchi

\section{Correction to: Chapter "Ultrastructural and Immunohistochemical Diagnosis of a Neonatal Herpes Simplex Virus Infection Presenting as Fulminant Hepatitis: A Case Report" in: V. Papa et al., Adv Exp Med Biol - Advances in Microbiology, Infectious Diseases and Public Health https://doi.org/10.1007/5584_2021_659}

This chapter was inadvertently published with the co-author name incorrectly spelt as Nunzio Cosimo Maria Salfi instead of it being rightly spelt as Nunzio Cosimo Mario Salfi. This has now been corrected. 